\title{
Facile purification of rare cucurbiturils by affinity chromatography
}

\author{
Sanjita Sasmal, ${ }^{a}$ Mantosh K. Sinha, ${ }^{\text {a,b }}$ and Ehud Keinan, ${ }^{\star, a, b, \#}$ \\ Department of Molecular Biology and The Skaggs Institute for Chemical Biology, The \\ Scripps Research Institute, 10550 North Torrey Pines Road, La Jolla, California 92037, \\ USA, Department of Chemistry and Institute of Catalysis Science and Technology, \\ Technion - Israel Institute of Technology, Technion City, Haifa 32000, Israel. \\ keinan@Scripps.edu
}




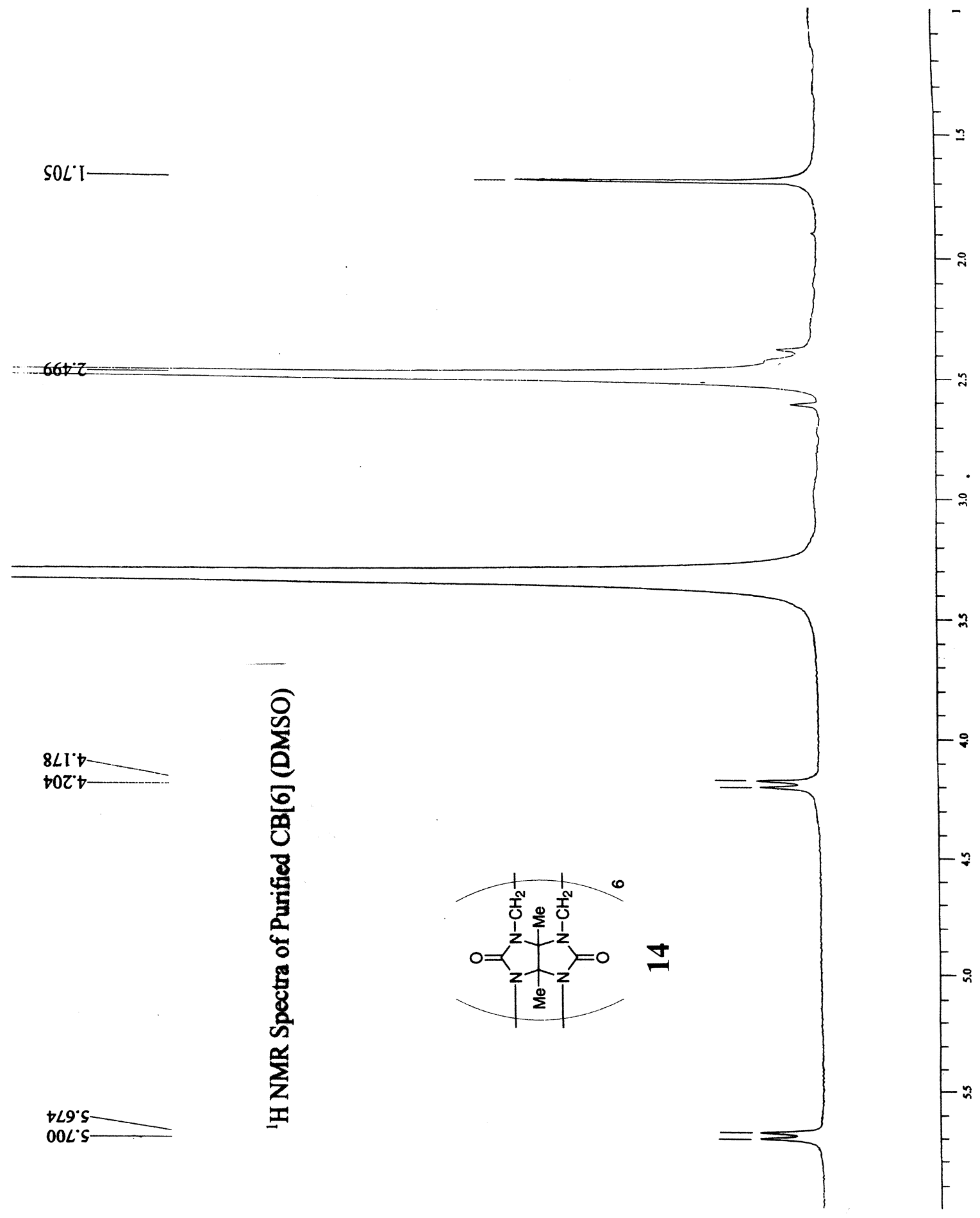




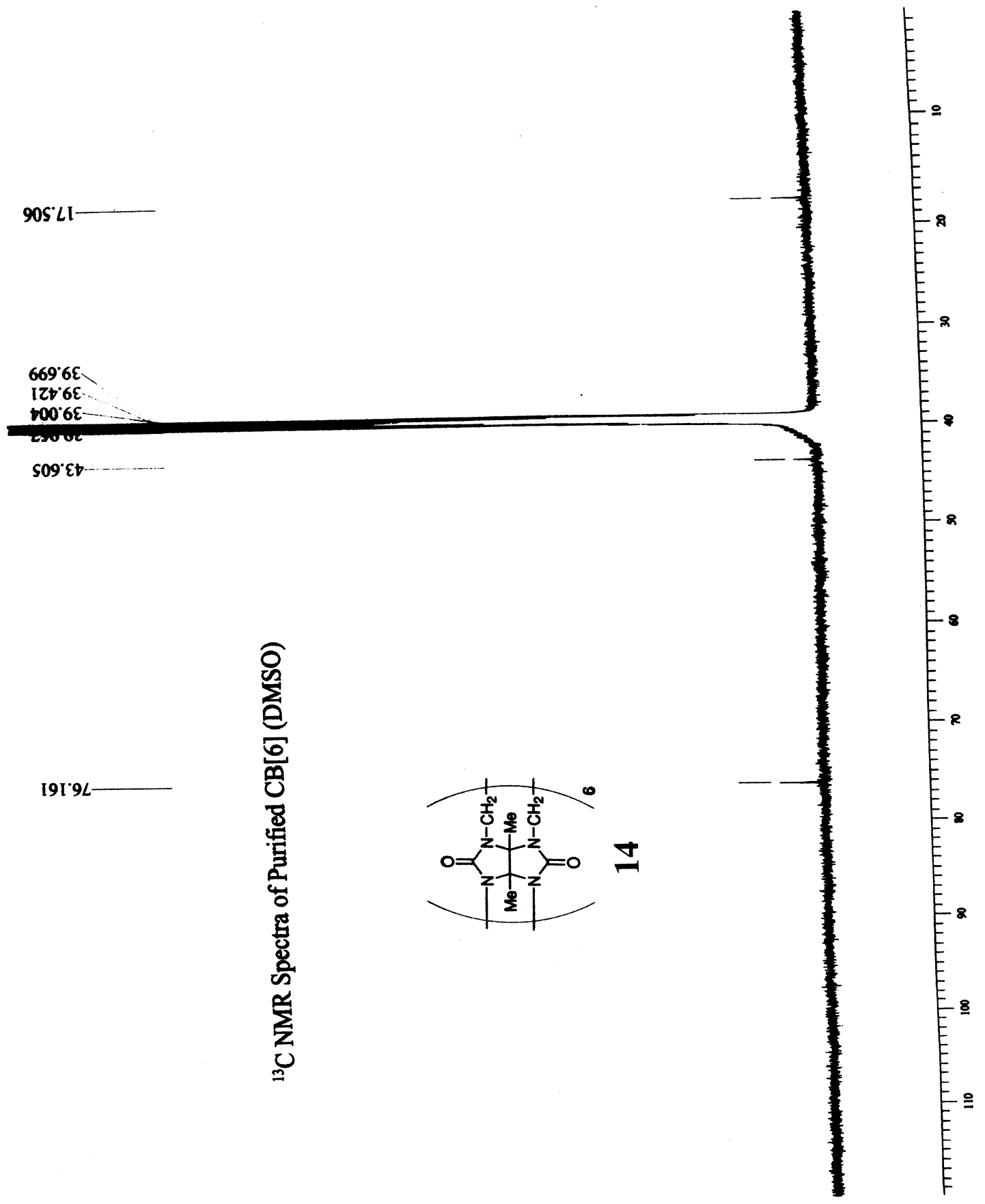




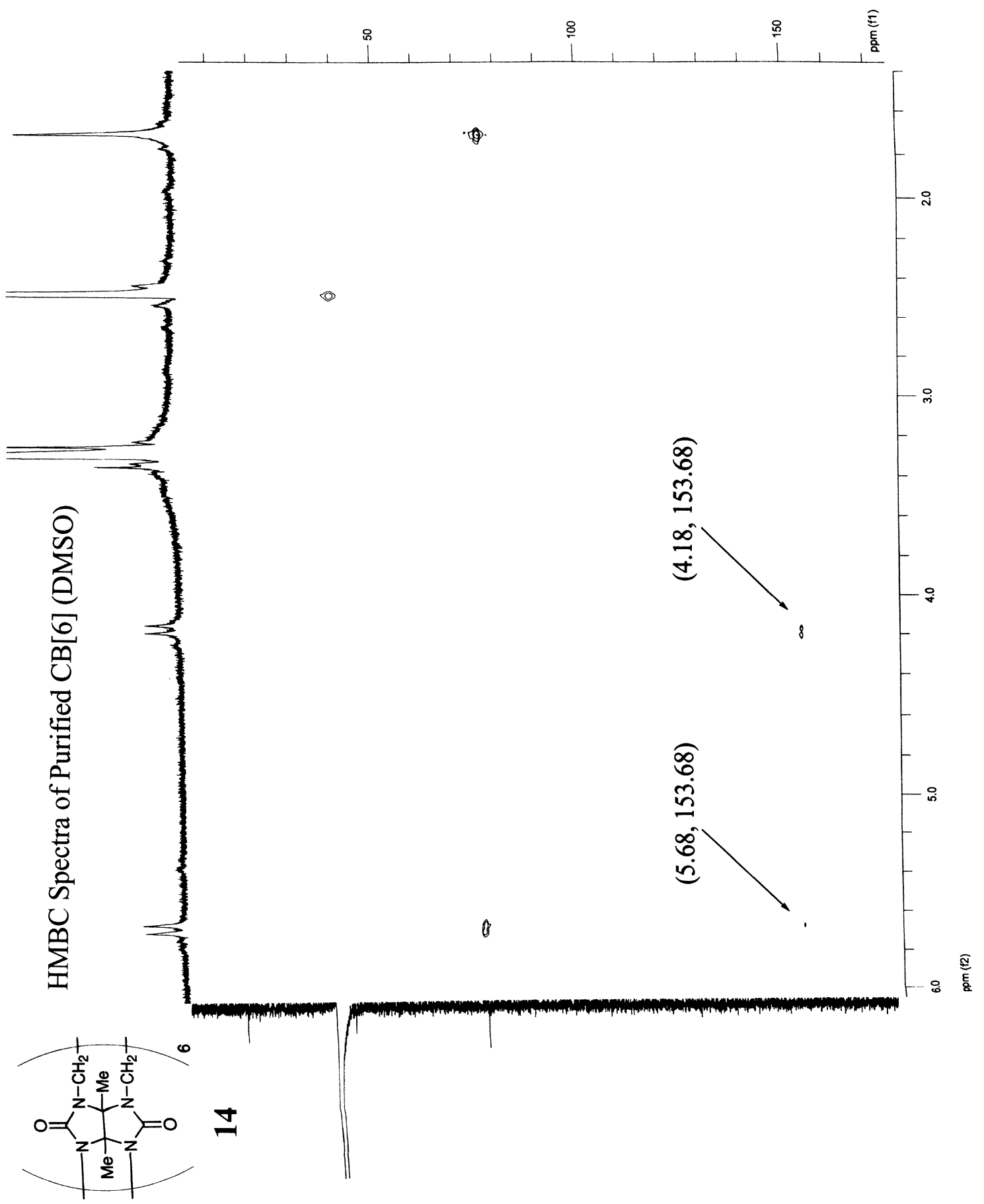




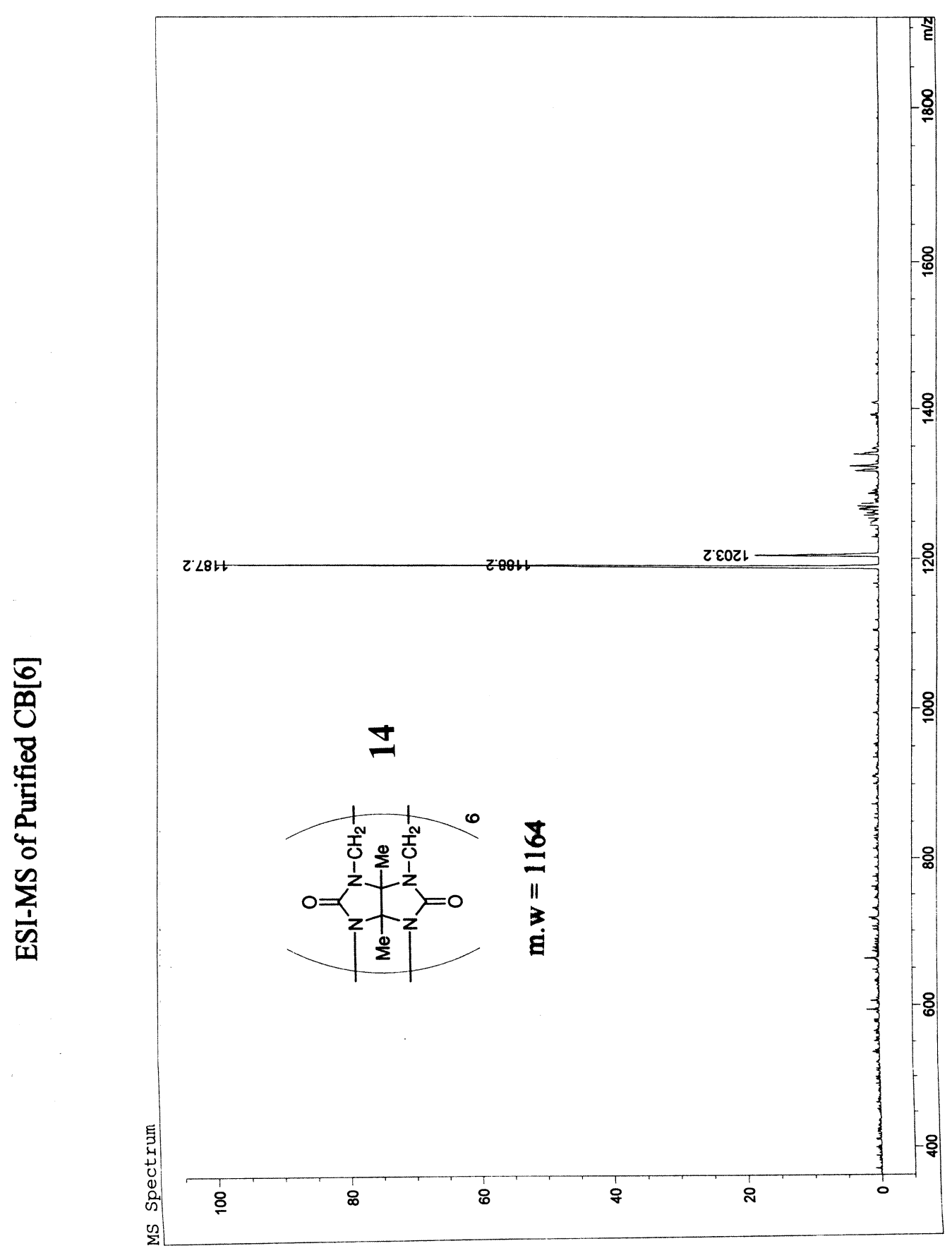




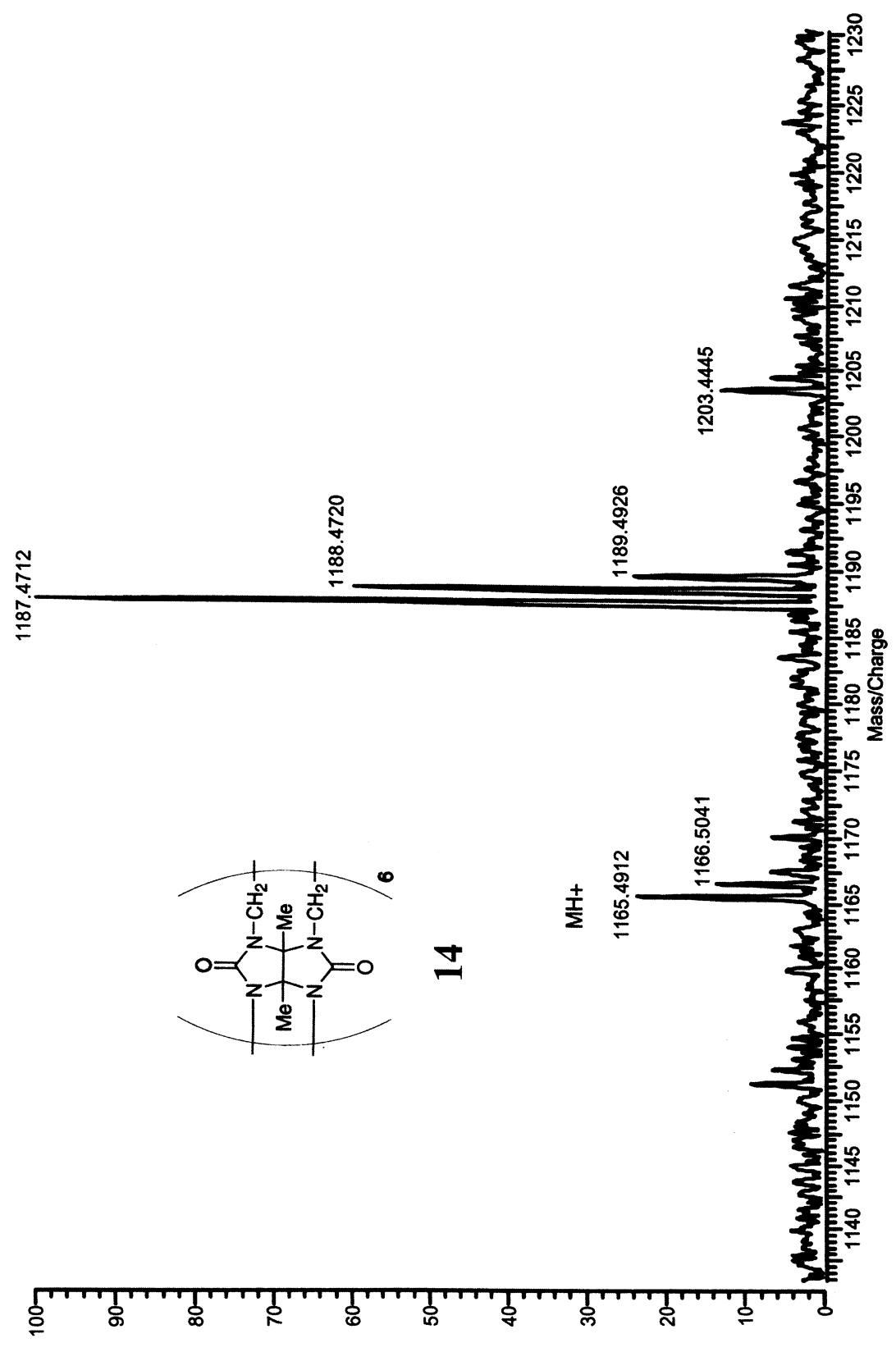




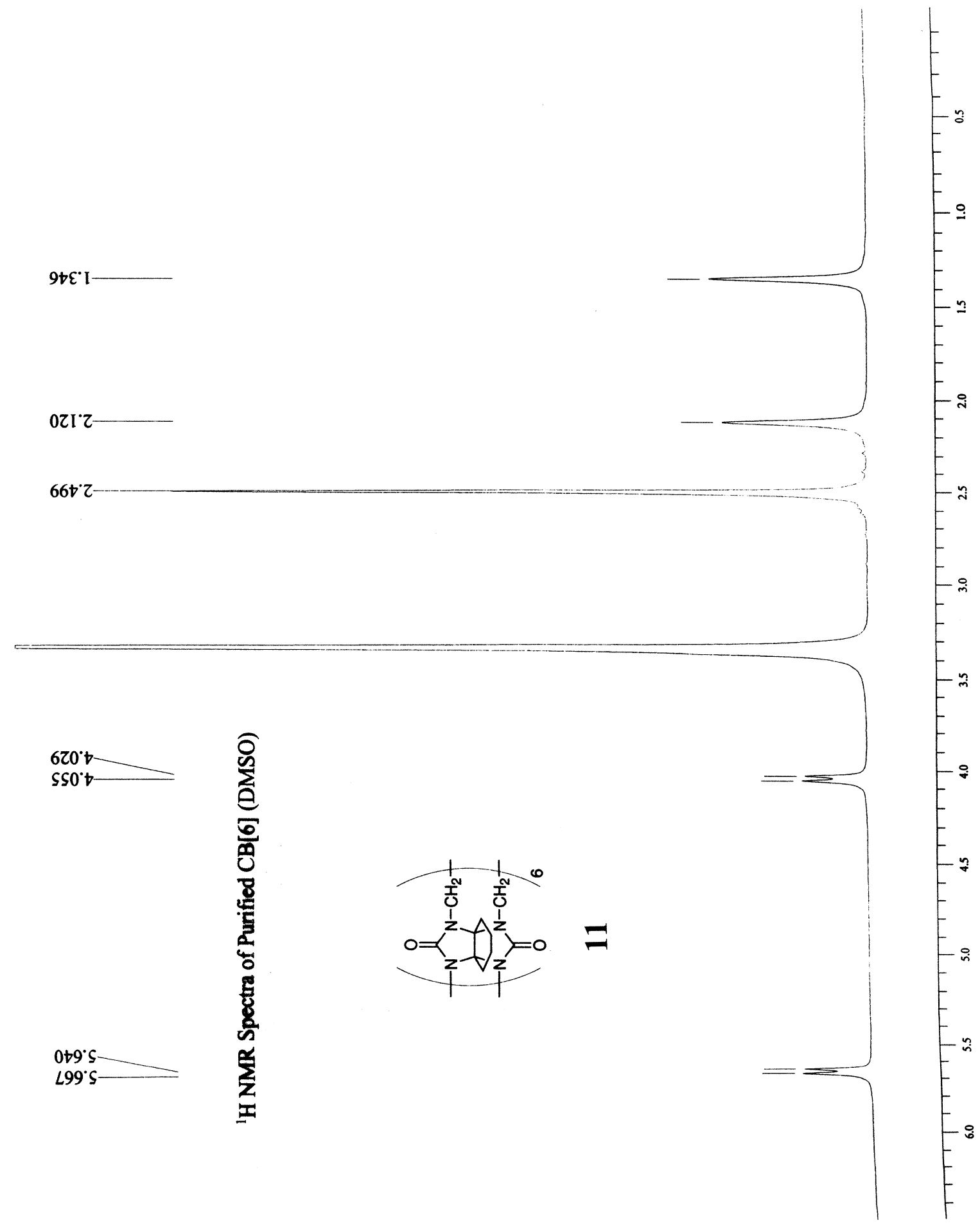




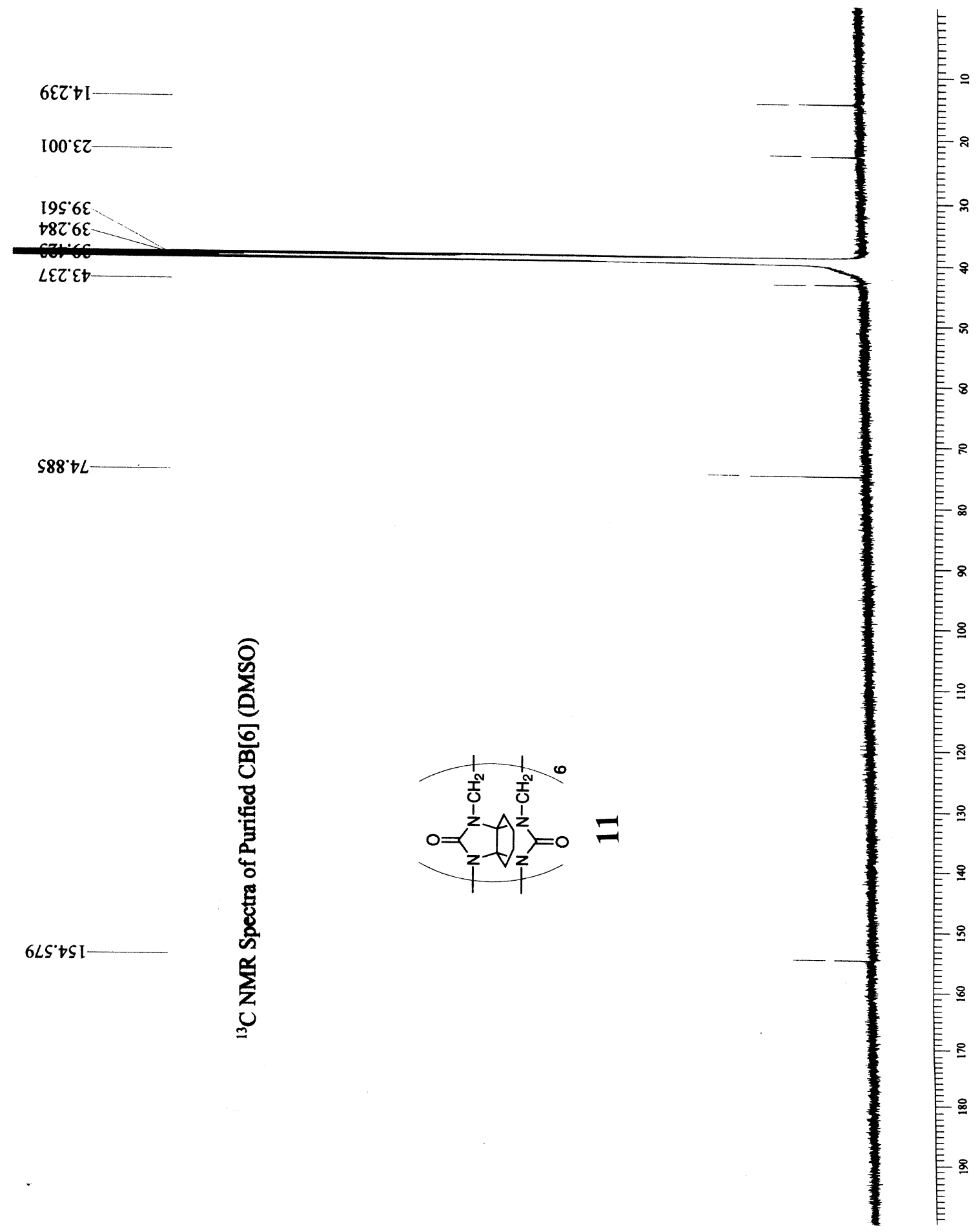




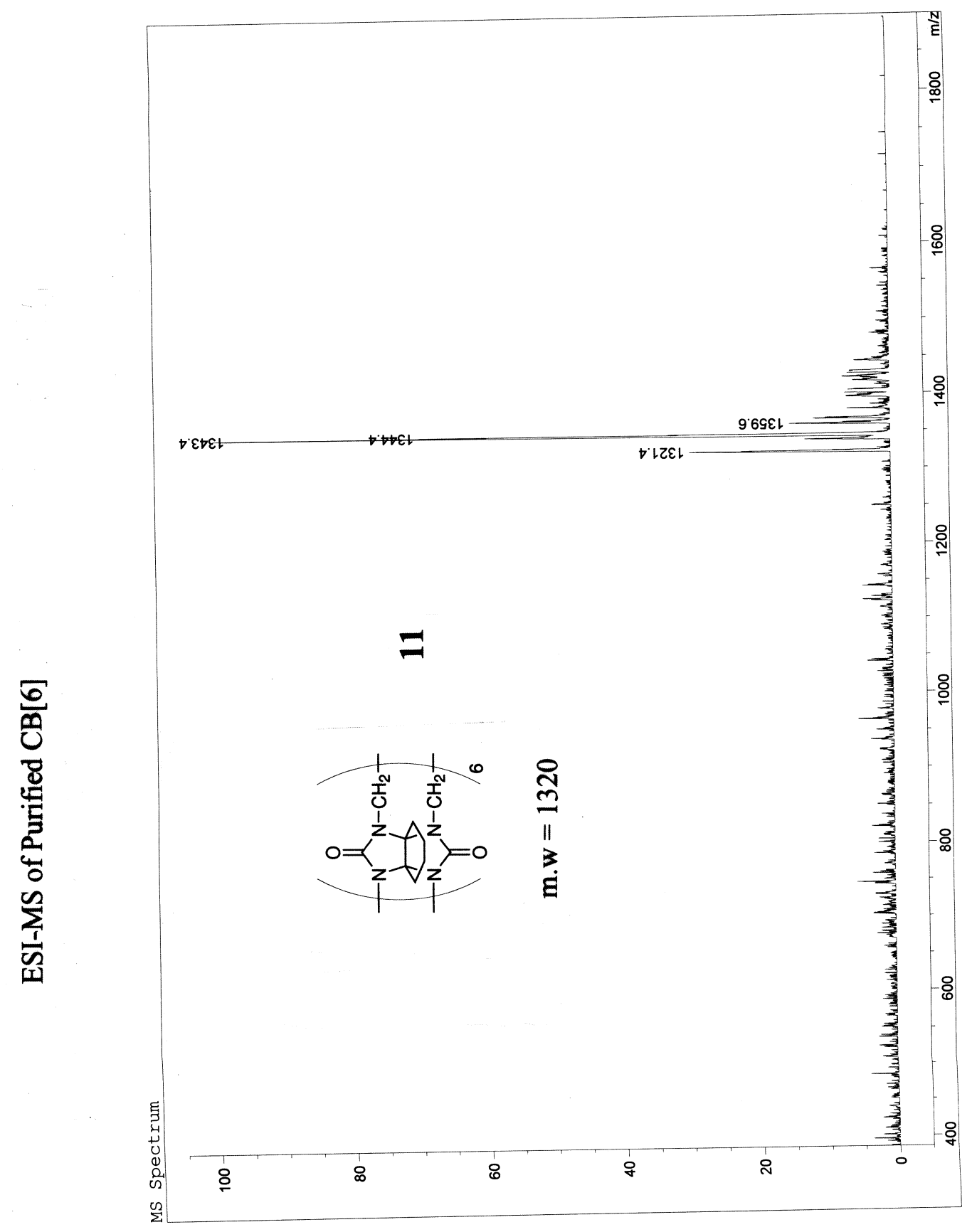




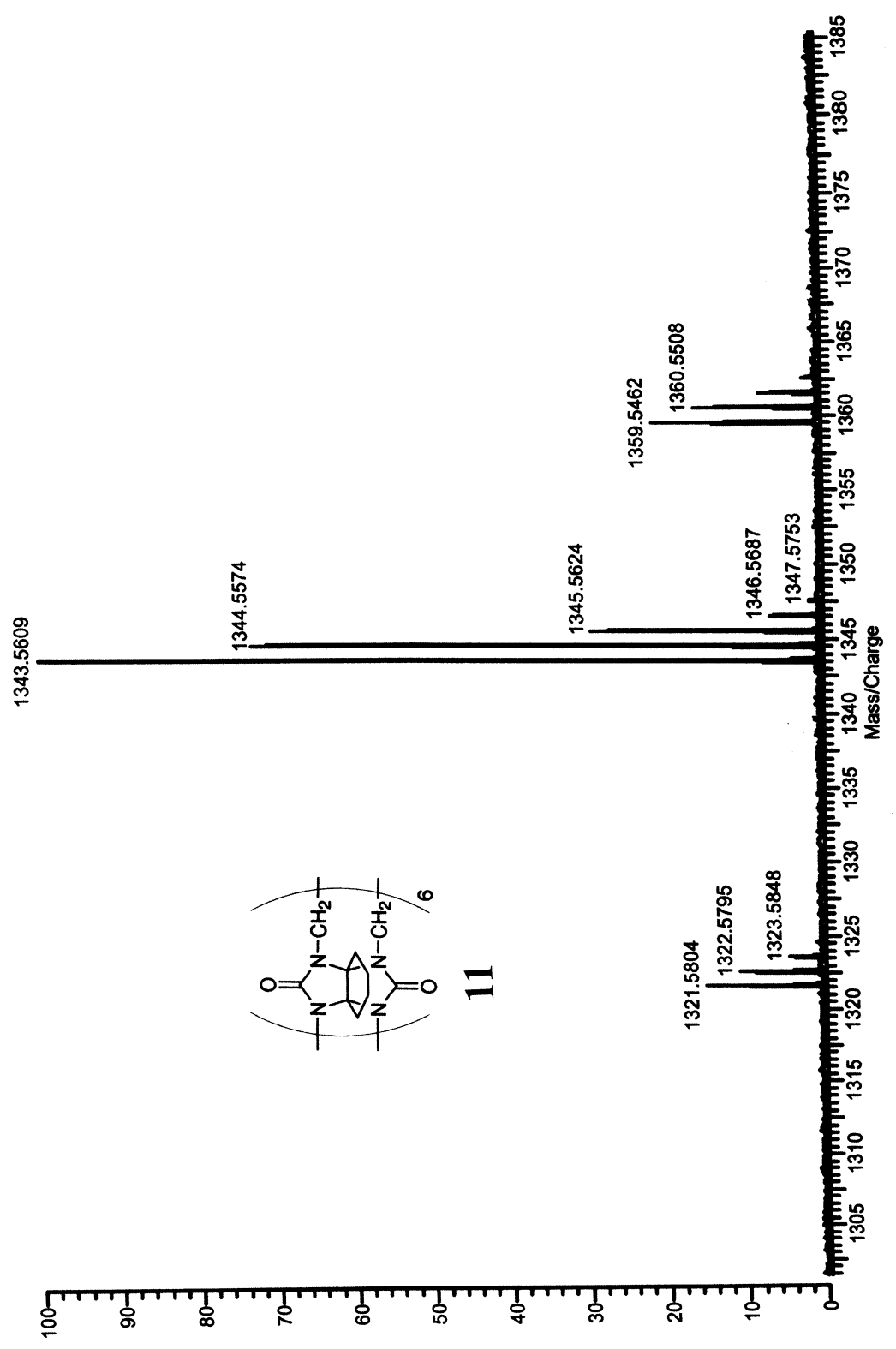




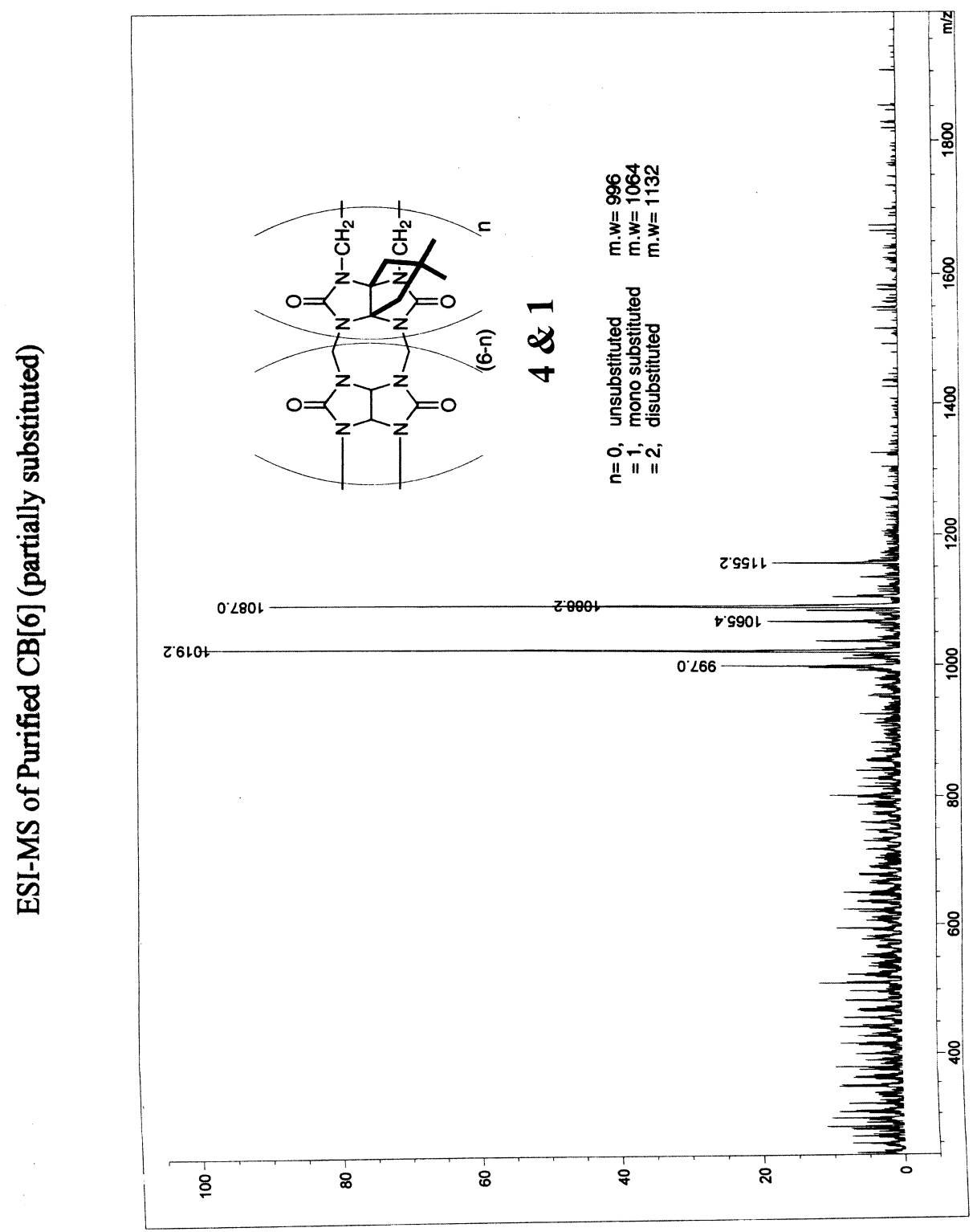




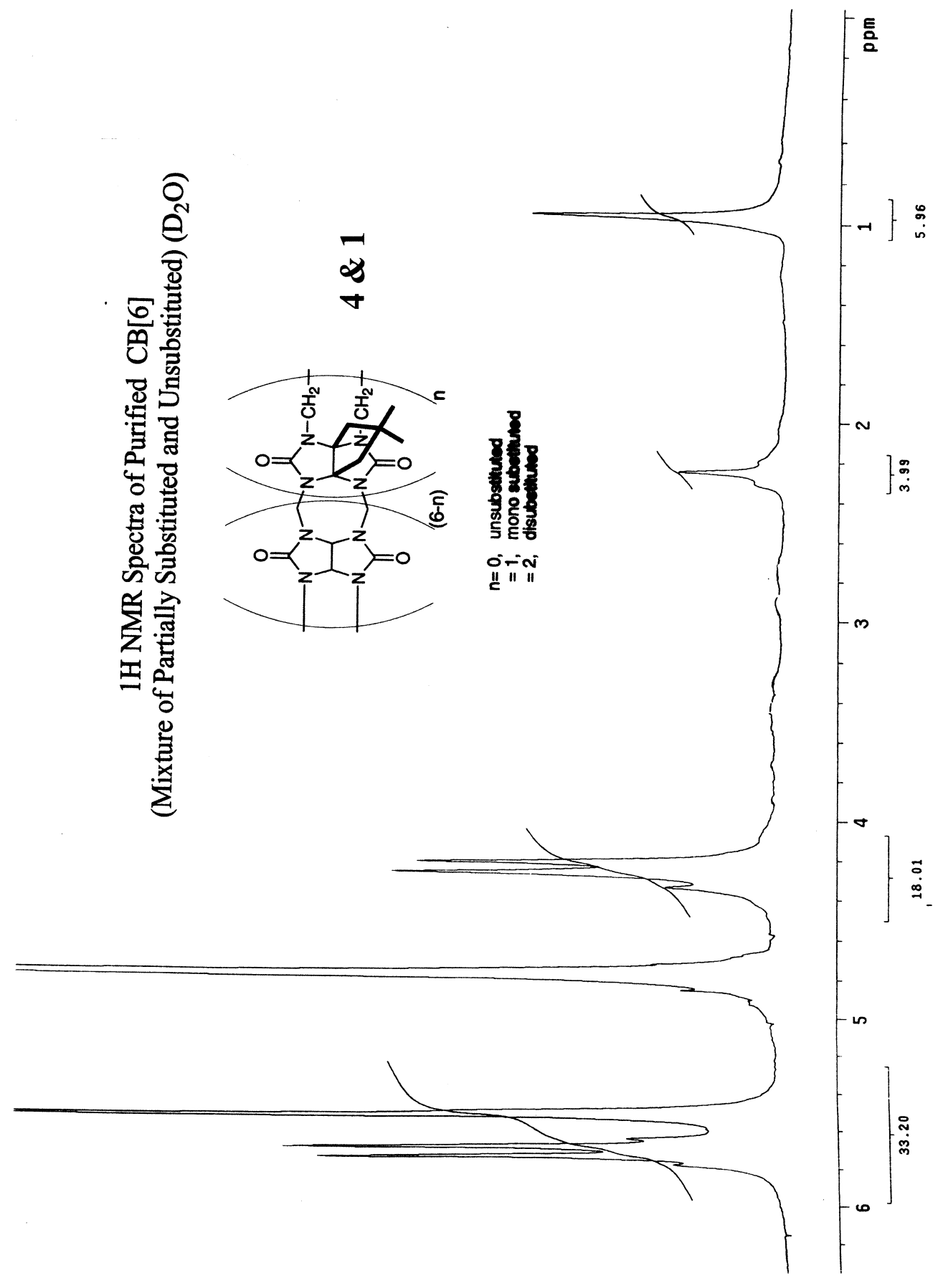




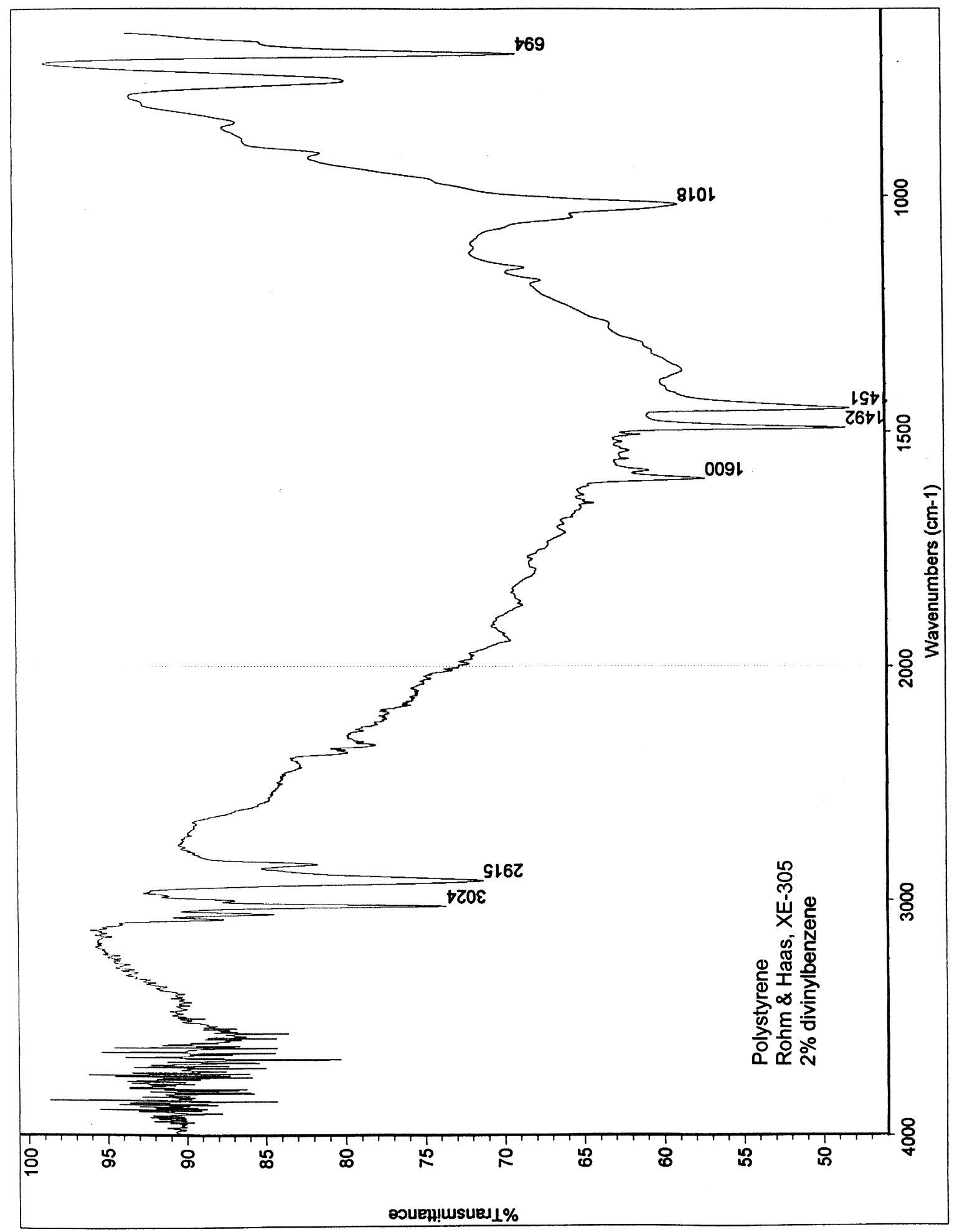




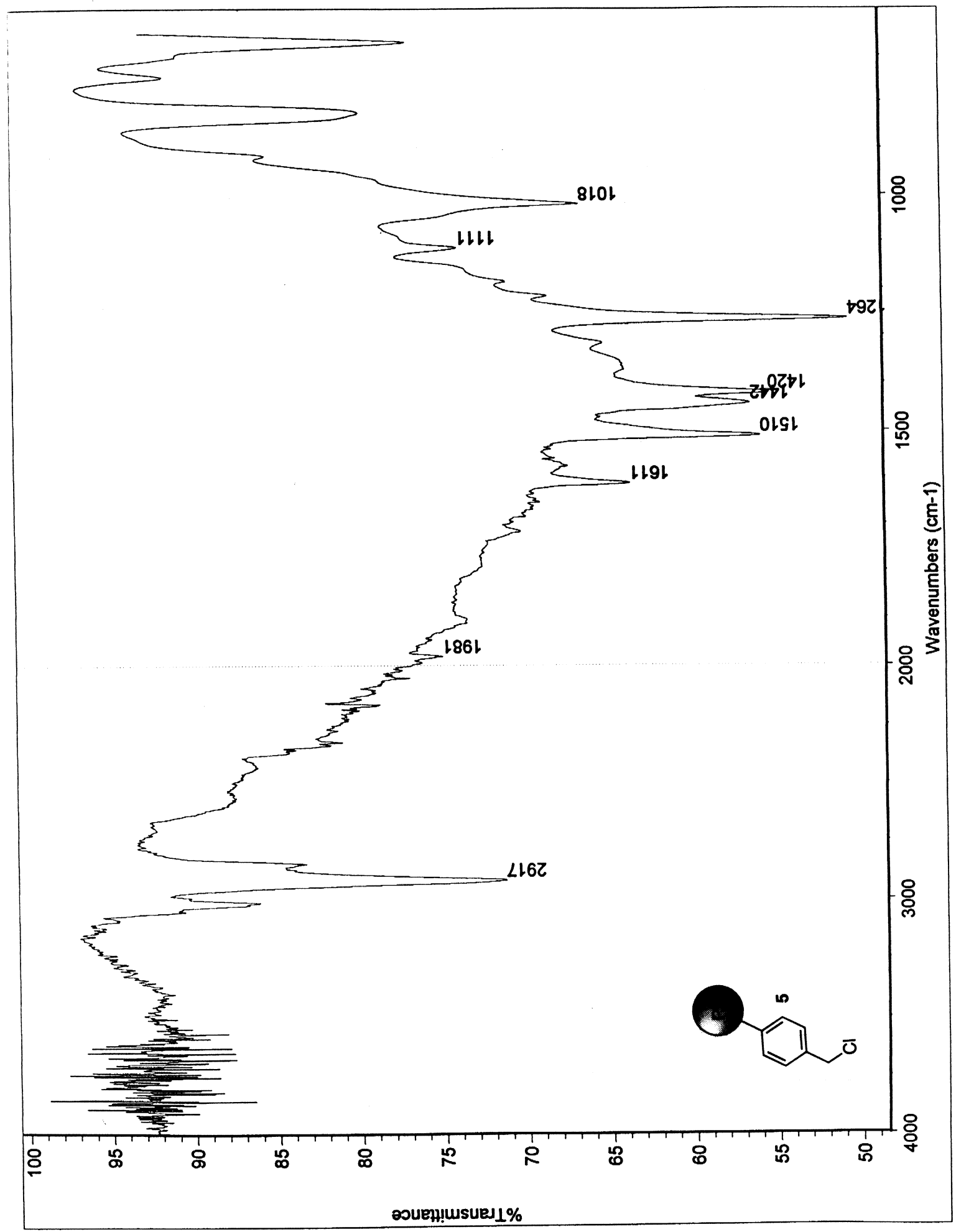




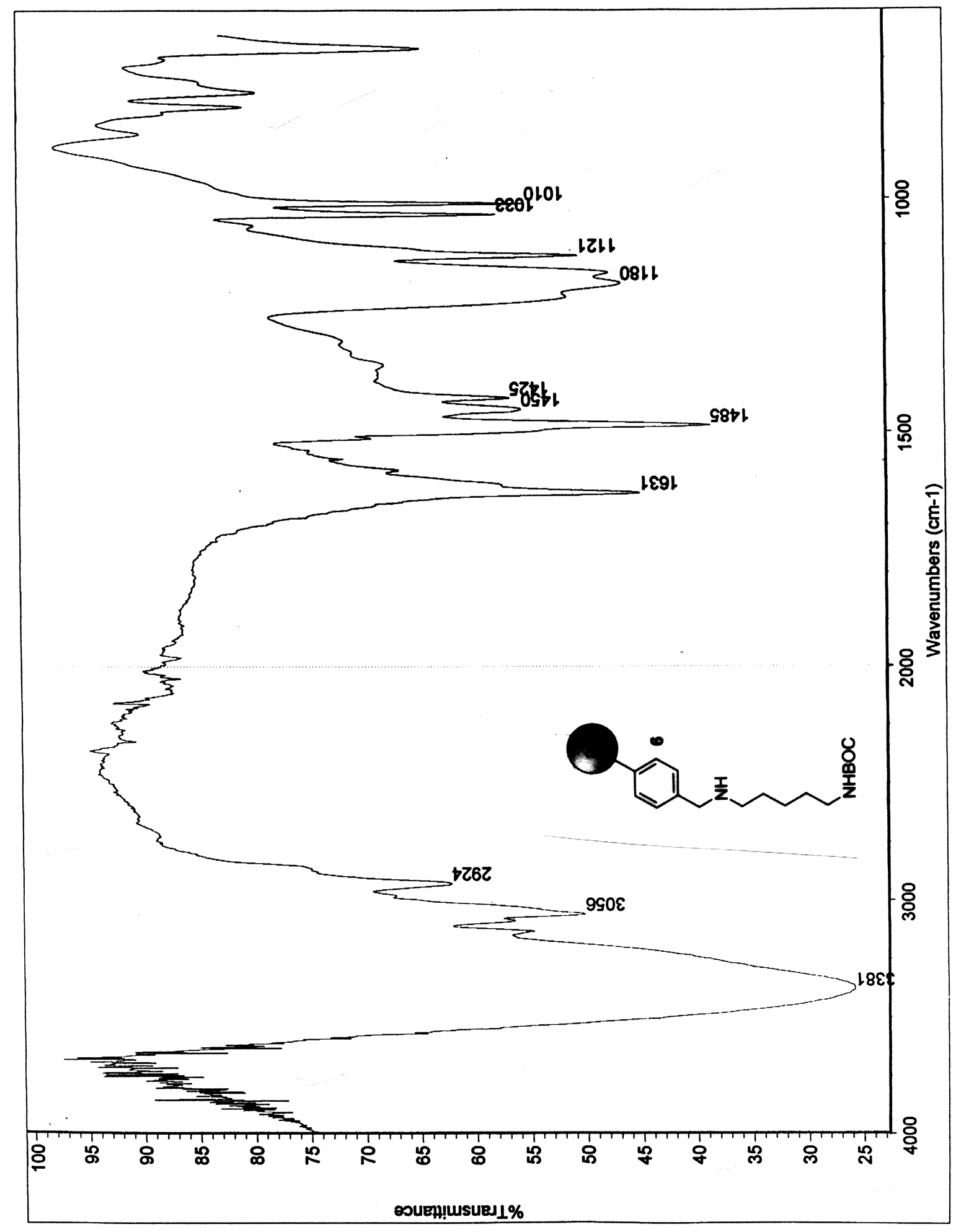




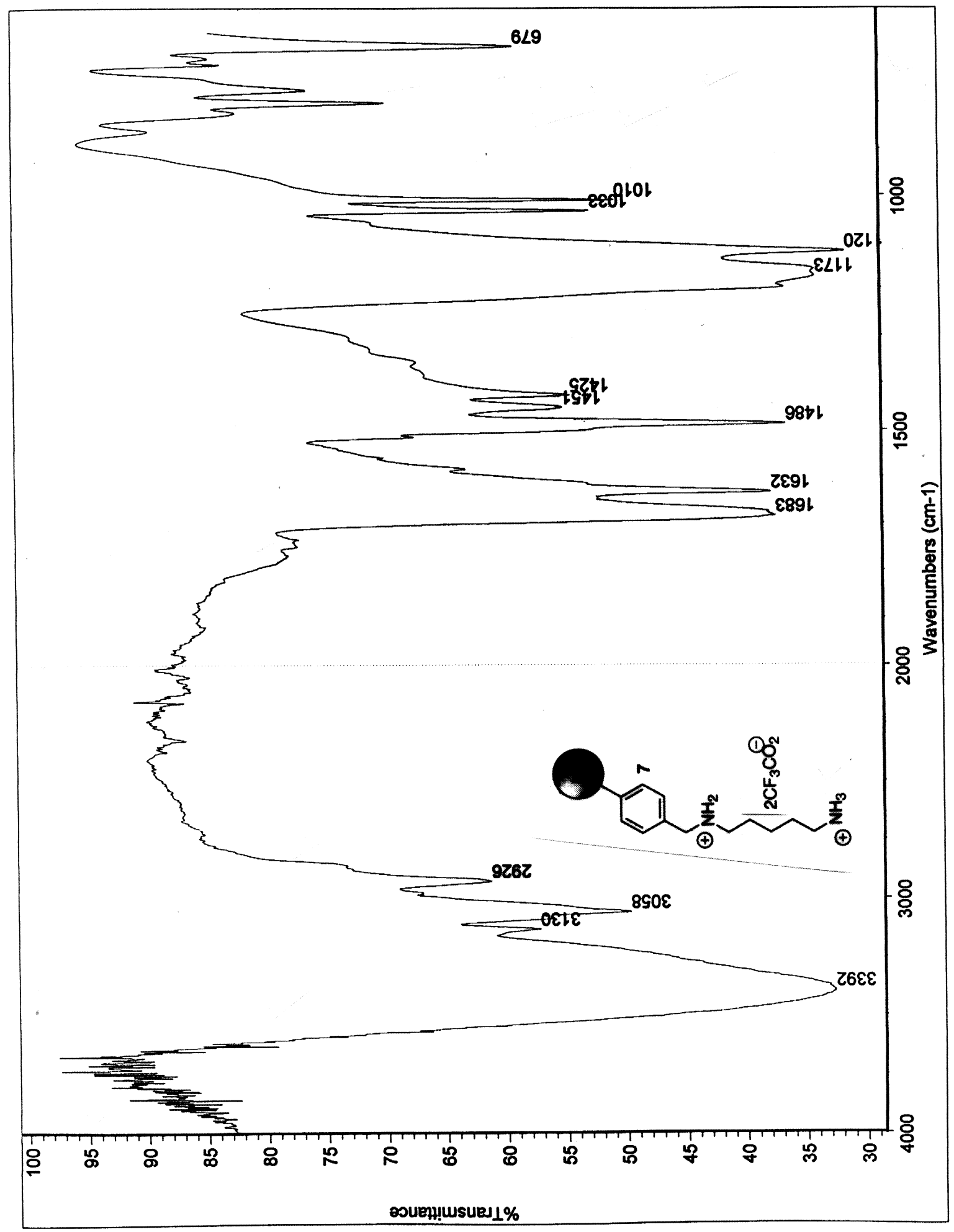




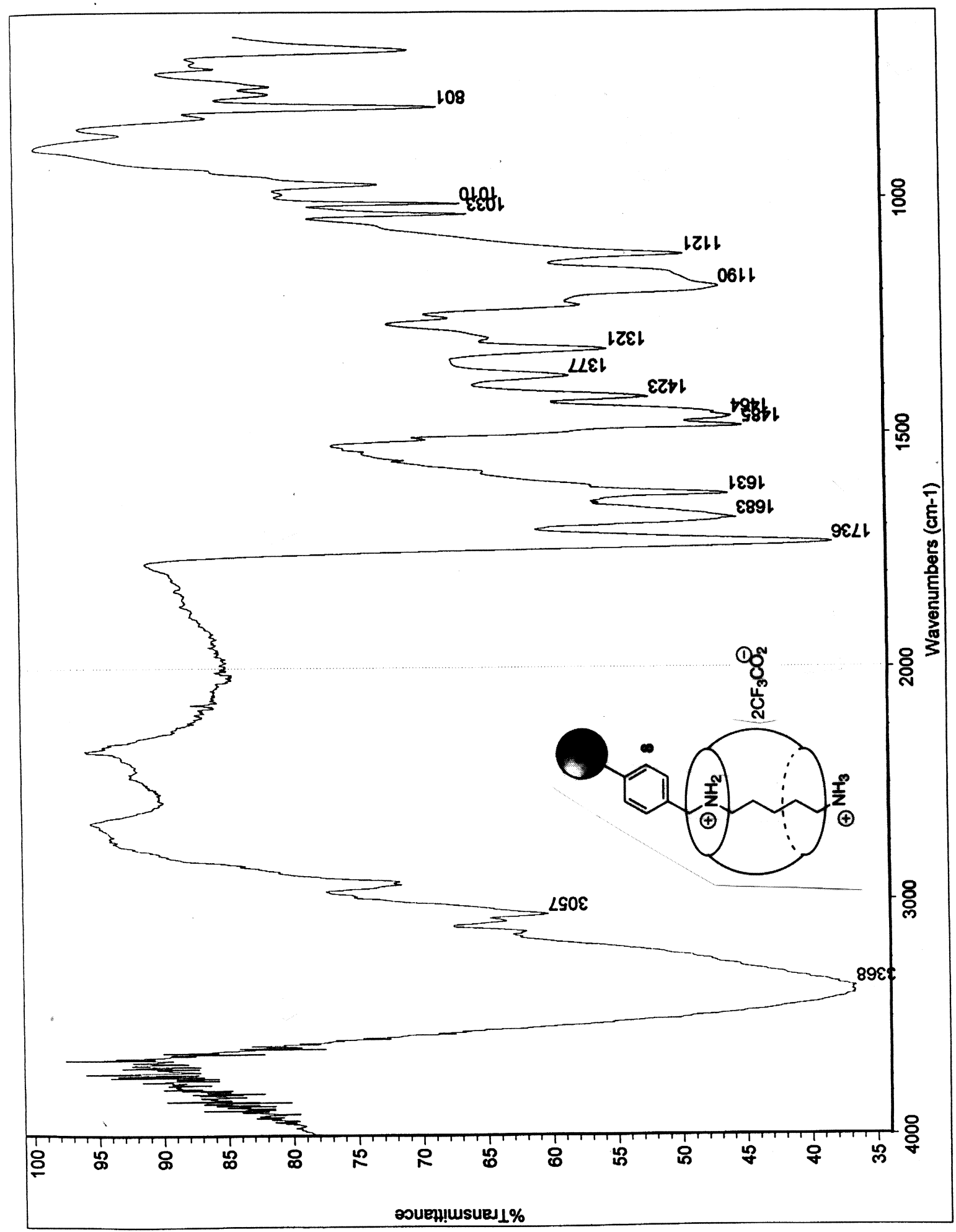




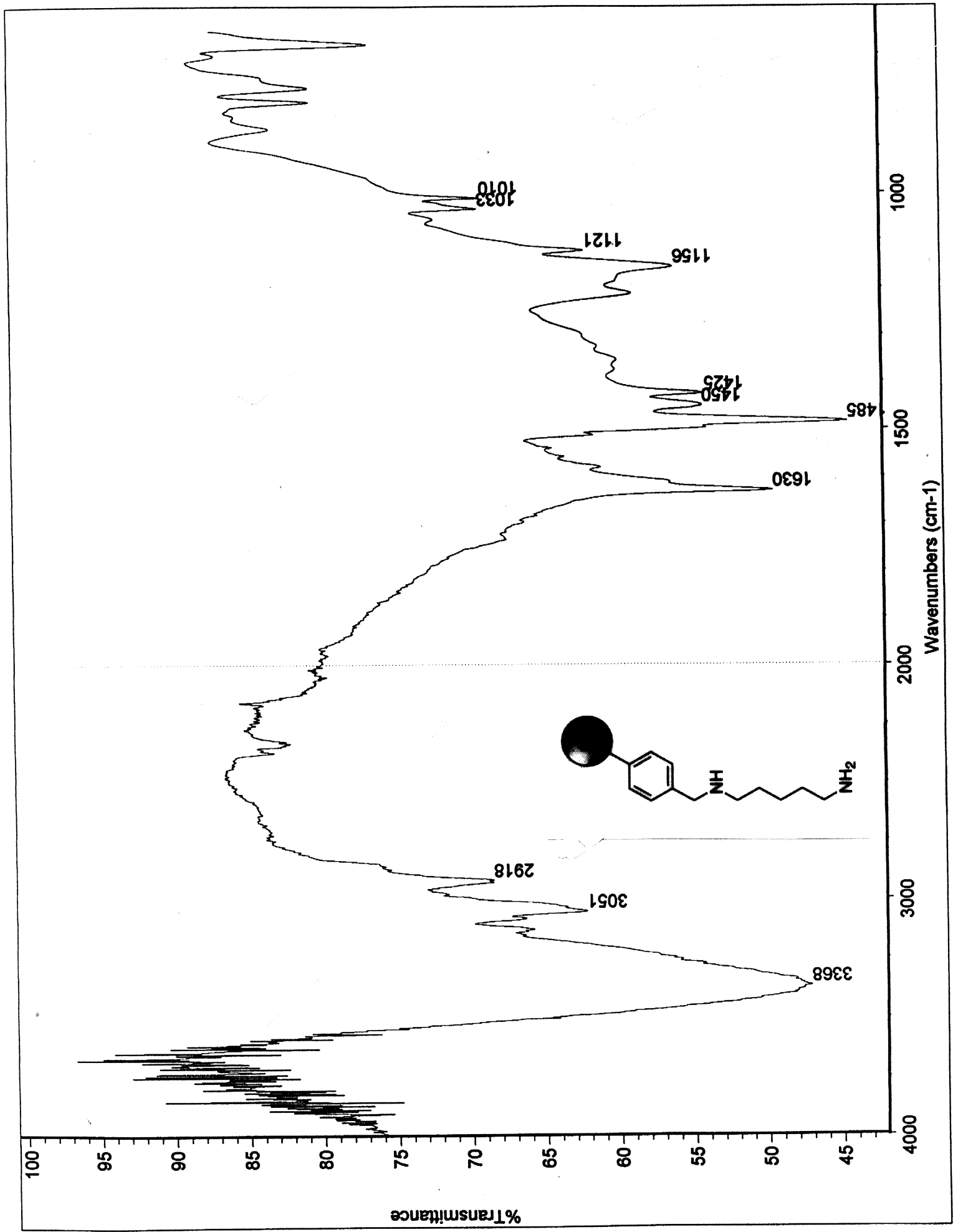

